International Journal of Design and Manufacturing Technology (IJDMT), ISSN 0976 - 6995(Print), ISSN 0976 - 7002(Online) Volume 2, Issue1, January-December (2011), pp. 21-27

(C) IAEME, http://www.iaeme.com/ijdmt.html

\title{
IMPROVEMENT IN MICRO HARDNESS OF M.S. (C-40) BY UTILIZING VIBRATORY TECHNIQUE IN ORDINARY BALL BURNISHING PROCESS
}

\author{
${ }^{1}$ Mayank K Patel, ${ }^{2}$ Prof. D. S. Kumani \\ ${ }^{1}$ M.Tech IV Sem (Production Engineering), ${ }^{2}$ Academic Dean \& Professor \\ Poornima college of Engineering - Jaipur \\ Corresponding Email: veeenmay@gmail.com
}

\begin{abstract}
Surface characteristic of material plays vital role in performance of a component such as load bearing capacity, fatigue strength, resistance to corrosion, friction, wear, etc. Some of parameters which influence the above performance characteristics are geometric features of the surface, its hardness, and degree of cold work and nature of residual stress induced. Burnishing forms an important member in the family of these post machining processes. The deforming action of the ball which governs the micro hardness is strongly governed by the trajectory movement of tool. The trajectory movement of tool can be adjusted in proper range by selecting proper combinations of speed, feed, vibration frequency and amplitude. Addition in vibratory technique, the investigation of electromagnetic vibrator using in ordinary ball burnishing process perform reliable and effective surface enhancement. The plastic deformation on the part surface can easily achieved by applying considerably lower pressure as compared to other conventional techniques. With the use of vibratory technique on lathe machine, further improvement is possible in micro hardness of work piece.
\end{abstract}

\section{Key words} hardness

Speed, feed, ball burnishing force, frequency, amplitude and micro

\section{INTRODUCTION}

Surface characteristic of material like surface roughness, surface hardness, fatigue strength etc. plays vital role in performance of a component. Some of parameters which influence the above performance characteristics are geometric features of the surface, its hardness, and degree of cold work and nature of residual stress induced in it [1][2]. 
International Journal of Design and Manufacturing Technology (IJDMT), ISSN 0976 - 6995(Print), ISSN 0976 - 7002(Online) Volume 2, Issue 1, January-December (2011), @ IAEME

For improves the surface characteristics of material as well as reliability of component, industries pay attention on surface finish and hardness of component. The various metal finishing processes can be mainly divided in two groups, group based on plastic deformation of surface layers, e.g. burnishing, shot peening, shot blasting, etc. and group based on cutting action of abrasives, e.g. grinding, polishing, lapping, honing, super finishing, etc.

Burnishing is a chip less metal finishing process in which a rotating roller or ball is pressed against metal piece as shown in fig. 1. It is a cold working process and involves plastic deformation under cold working conditions by pressing hard ball or roller. The burnishing process helps to improve surface finish and hardness. Burnishing is a process in which the peaks of metallic surfaces are displaced to fill the valleys by plastic deformation. This can simply achieved by pressing a hard and highly polished ball or roller against the surface of metallic work pieces [3][4].

In case of vibratory ball burnishing process, the burnishing tool is given an additional vibratory motion in the direction parallel to the axis of work piece with normal motion given in ordinary burnishing process. Vibratory motion of tool offers certain specific advantages on ordinary process like surface finishing as shown in fig. 2. Vibratory burnishing process improve the surface properties of material because it provide more complex trajectory movement of the deforming element related to the irregularities of the initial surface which are being deform. This is equivalent to super finishing process in which increase in the cutting ability of an abrasive grain is obtain by making the trajectory of its motion more complex relative to the surface being treated.

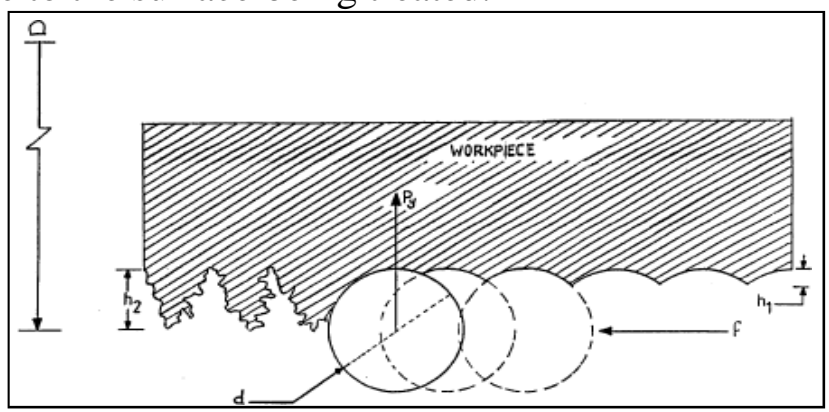

Fig. 1 The ball burnishing process

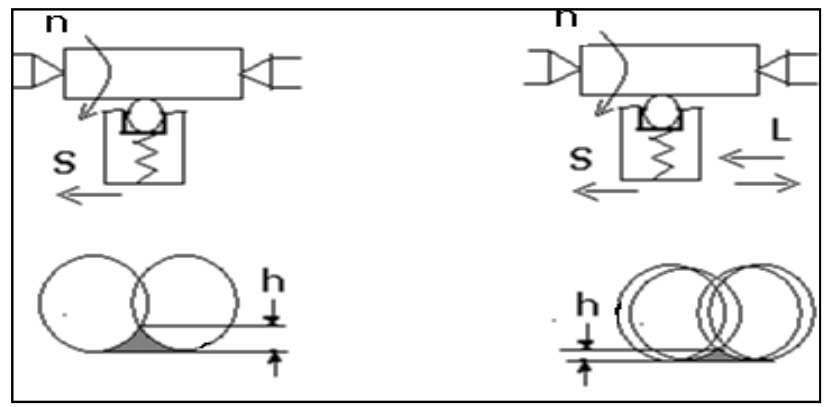

Fig. 2 Normal burnishing Vs Vibratory burnishing

The literature reveals that considerable attention is paid towards studying the influences of various process parameters on the surface 
International Journal of Design and Manufacturing Technology (IJDMT), ISSN 0976 - 6995(Print), ISSN 0976 - 7002(Online) Volume 2, Issue 1, January-December (2011), C IAEME

characteristics produced by normal burnishing process. Not much attempts have been made towards studying the influence of process parameters like speed, feed, burnishing force, frequency, amplitude of vibration on the surface characteristics like micro hardness.

The present paper aim at systematically studying the effect of process parameters like speed, feed, burnishing force, frequency and their interaction with micro hardness of the component using vibratory ball burnishing process. Experiments will be plan according to statistical design of experiment to improve the reliability of results.

\section{EXPERIMENTAL WORK DETAIL}

Experiments are being conducted on Banka make Loo-Type, S-8, Center lathe available at Machine Tool Laboratory [5]. The work piece was held in the three jaw chuck and burnishing tool was welded on the driver arm of vibratory unit which provides enough rigidity to the burnishing tool. After the fabrication of the ball burnishing tool and vibrator, the tool vibrator assembly was fitted in place of tool post on lathe bed. In the very first trial of the set up, it is found that vibrator give sufficient force to vibrate the tool. The experimental set up is designed as shown in figure 3 and 4 . The experimental set up consists of two elements: Single ball burnishing tool and Tool vibrating system

The flexible single ball burnishing tool is selected because it offers the following distinctive advantages like very easy to adjust and measure burnishing force directly by measuring the deflection of pre calibrated spring. In case of sudden increase in burnishing force, any damage to the burnishing tool or fixture arrangement can be avoided. Oscillation required in the vibratory process are mostly obtained either by mechanically (ultrasonic transducer or eccentrically load) or by electromagnet. The essential need in nature of oscillation used in vibratory burnishing process is that vibration can easily controllable as per requirement and oscillation gives sinusoidal grooves form on the surface layer of the work piece. These both basic requirements in the vibrations can satisfactorily fulfill by using electro magnet.

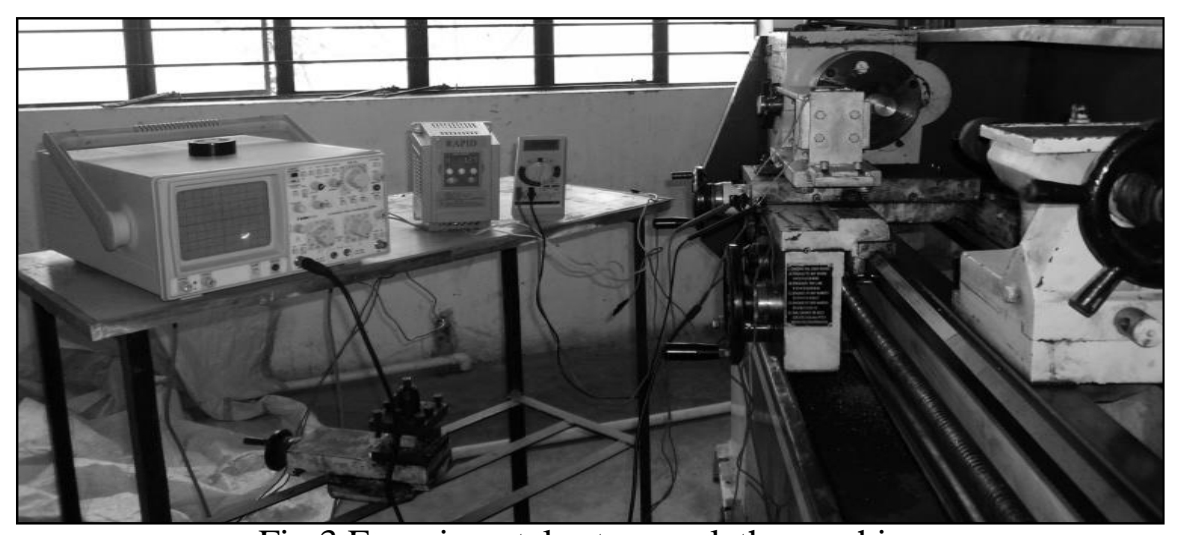

Fig.3 Experimental set up on lathe machine 
International Journal of Design and Manufacturing Technology (IJDMT), ISSN 0976 - 6995(Print), ISSN 0976 - 7002(Online) Volume 2, Issue 1, January-December (2011), @ IAEME

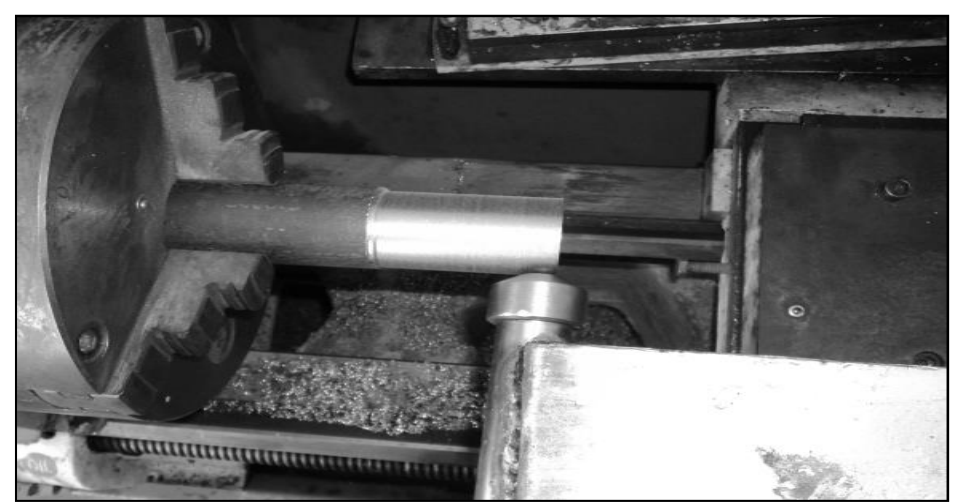

Fig.4 Engagement of ball tool with work piece

The burnishing tool was vibrated along the axis of the lathe by using an electrodynamic vibrator specially develops for this purpose. The vibrator was designed to produce the peak to peak force of $42 \mathrm{kgf}$ during vibration.

\section{Table 1 Experimental Condition}

1. Work material

2. Size of work piece

: M.S.(C-40), H.B. 170

3. Burnishing speed

: $\varnothing 30 \mathrm{~mm}$

4. Burnishing feed

: 60-304 rpm $(4.71-23.88 \mathrm{~m} / \mathrm{min})$

5. Burnishing force

: $0.07-0.24 \mathrm{~mm} / \mathrm{rev}$

6. Ball material

: 5 - $25 \mathrm{kgf}(50-250 \mathrm{~N})$

7. Size of ball

: Hardened alloy steel (Minimum HRC $=60$ )

8. Frequency

: $10.5 \mathrm{~mm}$

$: 10-50 \mathrm{~Hz}$

The frequency of vibration was adjusted with the help of AC Drive [6]. The amplitude of vibration during burnishing at various frequencies was measured with the help of oscilloscope.

\section{RESULT AND DISCUSSION}

Before carried out experiments based on statistical design technique, some prior experimental reading were conducted for deciding the significance of process parameters [4]. Mostly parameters choose on the basis of previous worked carried out on ordinary burnishing process.

\section{Influence of Burnishing Speed on micro hardness}

Fig. 5 shows the effect of speed on the micro hardness of surface layer. Reduction in speed causes an increase in micro hardness. This is because of the fact that the deforming action of the ball in vibratory process is greater at lower speed. 
International Journal of Design and Manufacturing Technology (IJDMT), ISSN 0976 - 6995(Print), ISSN 0976 - 7002(Online) Volume 2, Issue 1, January-December (2011), @ IAEME

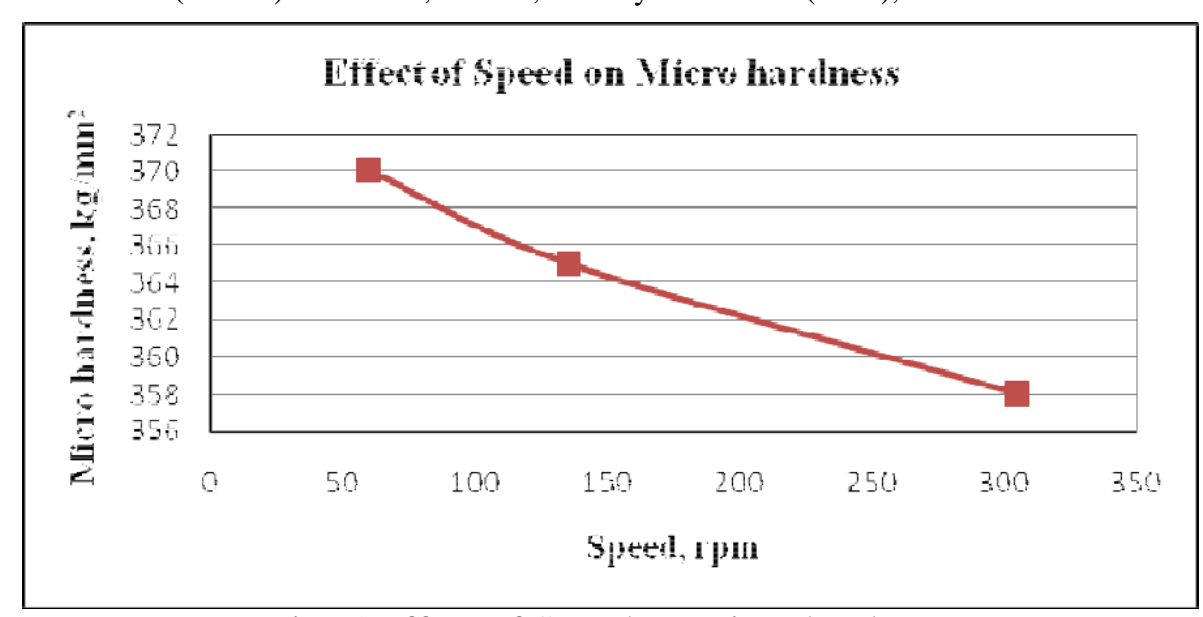

Fig. 5 Effect of Speed on micro hardness

In other words, at lower burnishing speed, the surface layer is plastically deformed to a greater depth because of comparatively more friction between ball element and work piece.

\section{Influence of Burnishing feed on micro hardness}

Fig. 6 shows the effect of feed on micro hardness. The highest value of micro hardness can be obtaining the feed range of $0.127 \mathrm{~mm} / \mathrm{rev}$ to $0.16 \mathrm{~mm} / \mathrm{rev}$. At very low feed of the order $0.07 \mathrm{~mm} / \mathrm{rev}$, the ball may passes over the same spot again and again leading to slipping phenomenon. This in turn, may lead to flaking of the layers and reduction in micro hardness. On the other end at very large feed surface hardness reduced as deforming element passes rapidly on surface of work piece.

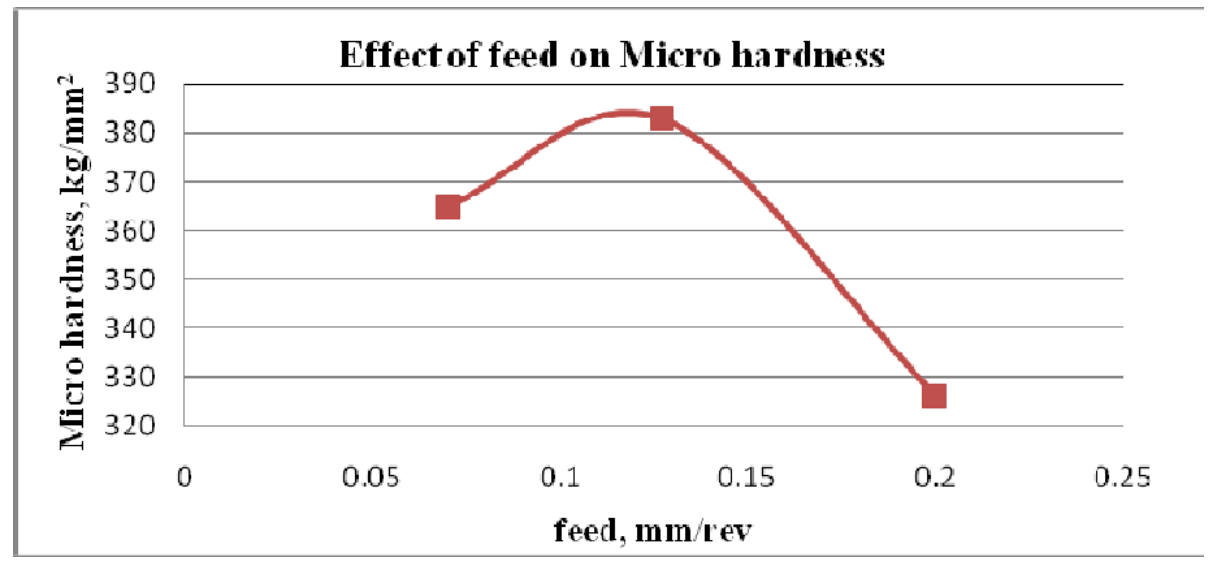

Fig. 6 Effect of feed on micro hardness

\section{Influence of Burnishing force on micro hardness}

Fig. 7 shows the effect of burnishing force on micro hardness. It is seen that up to certain limit micro hardness increase with increase in burnishing force and there after further increase in force micro hardness is reduced.

At lower burnishing force, the deforming action of the ball may insufficient to cause the requisite metal flow from the asperity peaks to valley. On the other hand, higher force may over stressing and over hardening of 
International Journal of Design and Manufacturing Technology (IJDMT), ISSN 0976 - 6995(Print), ISSN 0976 - 7002(Online) Volume 2, Issue 1, January-December (2011), @ IAEME

surface layer leading to particle break down, i.e. flaking of surface layers.

Similar result trends also been observed by A. M. Hassan [3], Pande, Patel [7].

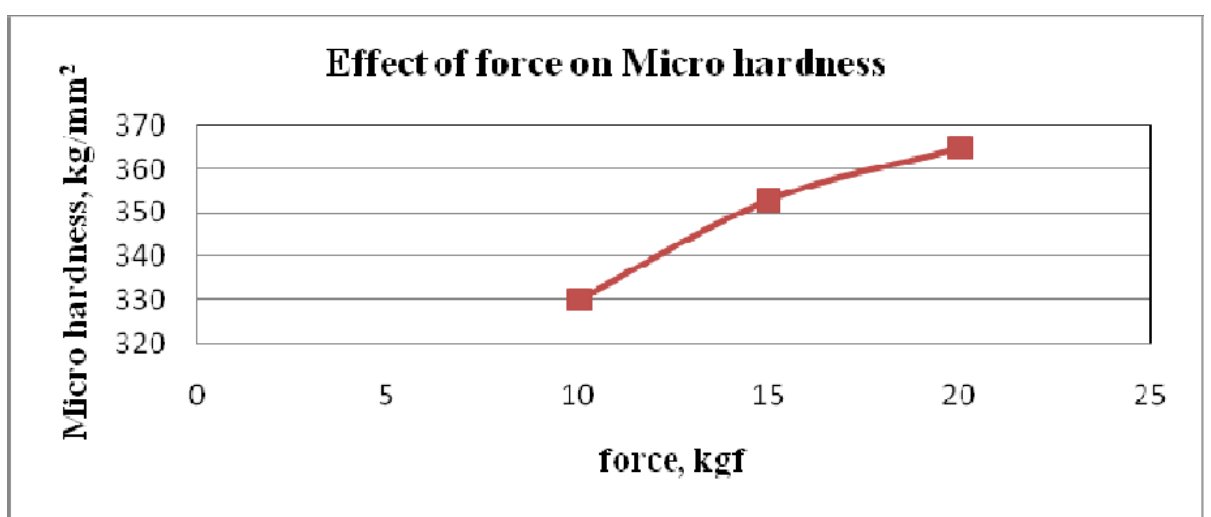

Fig. 7 Effect of force on micro hardness

\section{Influence of frequency on micro hardness}

Fig. 8 shows an effect of vibration frequency on the micro hardness of work piece. It is observed that highest micro hardness can be produced on the surface by adopting a combination of high frequency and low ball force and vice versa. i.e. with combination of low frequency (high amplitude) and high ball force.

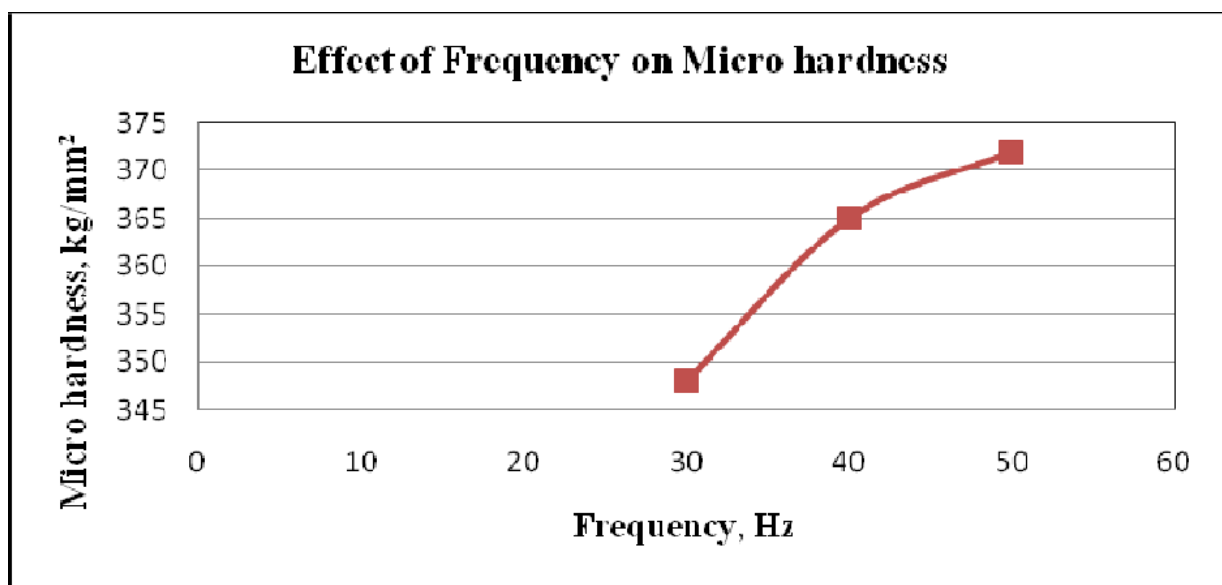

Fig. 8 Effect of frequency on micro hardness

\section{CONCLUSION}

The results of the Vibratory ball burnishing process are quite complicated, and many factors affect its results. How to find the optimal burnishing conditions and how to control the results are very important. According to this experimental work, the following conclusions may be drawn:

- Micro hardness of work piece obtain higher with a combination of lower frequency and lower burnishing force but with further increased force with higher frequency gives the better result. 
International Journal of Design and Manufacturing Technology (IJDMT), ISSN 0976 - 6995(Print), ISSN 0976 - 7002(Online) Volume 2, Issue 1, January-December (2011), @ IAEME

- The micro hardness $(\mathrm{H})$ of turned work piece was $232 \mathrm{~kg} / \mathrm{mm}^{2}$, which was improved up to $360 \mathrm{~kg} / \mathrm{mm}^{2}$ by normal burnishing. The highest experimental micro hardness of work piece is obtained $405 \mathrm{~kg} / \mathrm{mm}^{2}$ by vibratory ball burnishing tool with combination of $90 \mathrm{rpm}$ speed, 0.127 $\mathrm{mm} / \mathrm{rev}$ feed, $20 \mathrm{kgf}$ burnishing force and $40 \mathrm{~Hz}$ frequency.

- Micro hardness of turned work piece is improved 55\% with the help of normal burnishing tool and further improved $15 \%$ with the use of vibratory technique on centre lathe.

\section{REFERENCES}

[1] V.C.Venkatesh and Sudin Izman, "Precision Engineering" (2007), Tata McGraw-Hill Publishing Company Limited.

[2] HMT, Bangalore, "Production Technology" (2006), Tata McGraw-Hill Publishing Company Limited.

[3] A.M. Hassan, "An investigation into the surface characteristics of burnished cast a1-cu alloys" Int. J. Mech. Tools manufacturing. Vol. 37, no. 6, pp 813-821, 1997.

[4] Liviu luca, Sorin Neagu-Ventzel, Ioan Marinescu, "Effects of working parameters on surface finish in ball-burnishing of hardened steels" Precision engineering 29 (2005) 253-256.

[5] Manual "Lathe Banka" - 2010.

[6] Product catalogue of Rapid AC Drive 8800 - 2001.

[7] S.S.Pande, S.M.Patel, "Investigation on Vibratory Burnishing Process" Mechanical Tool Design 24 (1984) 195-206. 